\title{
THE EFFECTS OF INCOMPATIBILITY AND COMPATIBILITY ON GENOTYPE PROPORTIONS IN POPULATIONS OF THEOBROMA CACAO L.
}

\author{
F. W. COPE \\ Regional Research Centre, University College of the West Indies, \\ Imperial College of Tropical Agriculture, Trinidad
}

Received 7.viii.6 $\mathbf{1}$

\section{INTRODUCTION}

FROM an analysis of patterns of abscission and retention of handpollinated flowers on SI genotypes, Knight and Rogers (I953, I955) concluded that incompatibility in Theobroma cacao L. was under sporophytic control on both male and female sides. A single locus, showing multiple allelomorphism, appeared to be involved; and independence and dominance relationships, identical in male and female parts of the flower, existed between the $\mathrm{S}$ alleles. Their hypothesis is equivalent to Scheme J of Bateman (I952).

Cope (1962) showed that incompatibility in cacao has genetic control of the success or failure of syngamy as its basis. In incompatibly self- and cross-pollinated ovaries either one-quarter, one-half or all (sometimes not quite all) of the fertilized ovules show nonfusion between male gametes and their female counterparts. One-half of the male and female gametes are activated against syngamy when, at meiosis and segregation, they receive the parental dominant $\mathrm{S}$ allele; and all are activated in a homozygous genotype or in one with independent $\mathrm{S}$ alleles. The $\mathrm{S}$ locus apparently acts both before and after meiosis, since the overall reaction is one of sporophytic control, yet the gametes fuse, or fail to fuse, according to their haploid genotype. The single locus of Knight and Rogers is inadequate to explain certain results obtained by Cope, who postulated the existence of two accessory loci, $\mathrm{A} / a$ and $\mathrm{B} / b$, acting in a complementary manner with the S locus. Should one or more of the S, A and B loci become homozygous for an inactive mutant the SI condition is lost. Not only is the mutant genotype $\mathrm{SG}$ but it is reciprocally cross-compatible with any other genotype.

In dealing with equilibrium frequencies in his Scheme $\mathrm{J}$ for three $\mathrm{S}$ alleles Bateman (I952) states, "It can be shown that an equilibrium is obtained if $\mathrm{A}=\mathrm{B}=\mathrm{C}=\mathrm{I} / 3 \ldots " \mathrm{~A}, \mathrm{~B}$ and $\mathrm{C}$ are, in fact, the frequencies of the $S_{1}, S_{2}$ and $S_{3}$ phenotypes, respectively, so that the statement implies the existence of equilibrium when the three phenotypes are equally frequent. This simple relationship between phenotype proportions is true also of the case of only two alleles $\left(\mathrm{S}_{1}>\mathrm{S}_{2}\right)$ here equilibrium frequencies for $S_{1.2}$ and $S_{2.2}$ would be each one-half. Equilibrium frequencies in populations containing four and five $S$ alleles in serial dominance were calculated, and again it was found 
that all phenotypes occur in equal abundance at equilibrium. The analysis was then extended to cover the general case of a population with $n$ alleles in serial dominance. Expressions were obtained for computing the equilibrium proportions of the component genotypes. Theoretical studies were also undertaken of the effect of the presence of the $\mathrm{S}_{f}$ amorph in a cacao population containing both SC and SI types; the amorph is an inactive mutant of the $S$ series which when homozygous imparts self-compatibility and is recessive to all active $\mathrm{S}$ alleles.

Apart from Bateman's publication of the genotype proportions and allele frequencies at equilibrium in a tri-allele example of his Scheme J, no other analyses of this type appear to have been published. Although the theoretical studies have been made for populations of $T$. cacao, in which the site of the incompatibility reaction lies in the embryo-sac, they would be applicable to any case in which control is sporophytic in both pollen and style and operated by means of an allelomorphic series showing dominance and independence relationships the same in male and female parts.

\section{SELF-INCOMPATIBLE POPULATIONS}

In a population which has $n$ different $\mathrm{S}$ alleles in serial dominance $\left(\mathrm{S}_{1}>\mathrm{S}_{2}>\mathrm{S}_{3}>\ldots \mathrm{S}_{r}>\ldots>\mathrm{S}_{n}\right)$ there will be $\frac{1}{2}(n-1)(n+2)$ genotypes, $n-1$ of which will be homozygotes - the homozygous top-dominant does not exist. The genotypes will fall into $n$ phenotypic groups, intra-incompatible and inter-compatible. Reciprocal pollinations will yield identical results, since the $\mathrm{S}$ series shows the same dominance relationships in male and female parts; for this reason, table I, which presents the progeny genotypes which will emerge on systematic cross-pollination, is symmetrical about the diagonal from the top left-hand corner. Only half of the entries are therefore shown, and only the first four phenotypic groups are presented.

Using the Roman and Greek letters of table I to indicate genotype and phenotype proportions, respectively, and assuming that all genotypes are equally viable, it is not difficult to show that the condition that the $S_{1}$ phenotype maintains equilibrium is

$$
\alpha=\alpha^{2}+\beta^{2}+\gamma^{2}+\ldots
$$

Turning to the $S_{1.2}$ and $S_{2.2}$ genotypes, we find that their relative frequencies remain constant, after one cycle of systematic mating, if

and

$$
\begin{aligned}
& \alpha(\beta+e)=2 a(\mathrm{I}-\alpha) \\
& a(\beta+e)=2 e(\mathrm{I}-\alpha)
\end{aligned}
$$

The $\mathrm{S}_{2}$ phenotype, it can be shown, maintains some constant proportion, $\beta$, if

$$
(\beta+e)(\alpha-a)+2(\beta+e)(\mathrm{I}-\alpha-\beta)+2 a(\mathrm{I}-\alpha)=2 \beta(\mathrm{I}-\alpha)
$$


which, by virtue of $(2)$ and $(3)$, reduces to

$$
(\beta+e)(\mathrm{I}-\beta)=(\beta+e)(\mathrm{I}-\alpha)
$$

whence, since $\beta+e \neq 0, \quad \beta=\alpha$

The condition, therefore, that the $S_{2}$ phenotype maintains the same relative frequency from one generation to the next is that its proportion in the population shall be the same as that of the $S_{1}$ phenotype.

\section{TABLE ,}

\section{Segregation of genotypes from matings between self-incompatible cacao parents}

The table covers only the first four phenotypes whose proportions in the population are denoted by $\alpha, \beta, \gamma, \delta$. Parental genotype proportions are denoted by $a, b, c \ldots q$. The crosses indicate incompatible combinations. $1 \cdot 2,2.5$, etc., in the body of the table are used in abbreviation for $\mathrm{S}_{1 \cdot 2}, \mathrm{~S}_{2 \cdot 5}$, etc.

\begin{tabular}{|c|c|c|c|c|c|c|c|c|c|c|c|c|c|}
\hline \multirow{3}{*}{$a \mathrm{~S}_{1 \cdot 2}$} & \multicolumn{4}{|c|}{$\alpha$} & \multicolumn{4}{|c|}{$\beta$} & \multicolumn{3}{|c|}{$\gamma$} & \multicolumn{2}{|c|}{$\delta$} \\
\hline & $\mathrm{S}_{1 \cdot 2}^{a}$ & $\mathrm{~S}_{1 \cdot 3}^{b}$ & $\mathrm{~S}_{1 \cdot 1}^{c}$ & $\begin{array}{c}d \\
\mathrm{~S}_{1.5}\end{array}$ & $\mathrm{~S}_{2 \cdot 2}^{e}$ & $\underset{\mathrm{S}_{2 \cdot 3}}{f}$ & $\stackrel{g}{S_{2 \cdot 4}}$ & $\begin{array}{c}h \\
\mathrm{~S}_{2 \cdot 5}\end{array}$ & $\begin{array}{c}k \\
\mathrm{~S}_{3 \cdot 3}\end{array}$ & $\begin{array}{c}m \\
\mathrm{~S}_{3 \cdot 4}\end{array}$ & $\mathrm{~S}_{3 \cdot 5}^{n}$ & $\mathrm{p}_{\mathrm{s} \cdot 1}^{p}$ & $\mathrm{~S}_{4 \cdot 8}^{q}$ \\
\hline & $x^{\prime}$ & $x$ & $x$ & $x$ & $\begin{array}{l}1 \cdot 2 \\
2 \cdot 2\end{array}$ & $\begin{array}{ll}1 \cdot 2 & 1 \cdot 3 \\
2 \cdot 2 & 2 \cdot 3\end{array}$ & $\begin{array}{cc}1 \cdot 2 & 1 \cdot 4 \\
2 \cdot 2 & 2 \cdot 4\end{array}$ & $\begin{array}{ll}1 \cdot 2 & 1 \cdot 5 \\
2 \cdot 2 & 2 \cdot 5\end{array}$ & $\begin{array}{l}1 \cdot 3 \\
2 \cdot 3\end{array}$ & $\begin{array}{cc}1 \cdot 3 & 1 \cdot 4 \\
2 \cdot 3 & 2 \cdot 4\end{array}$ & $\begin{array}{cc}1 \cdot 3 & 1 \cdot 5 \\
2 \cdot 3 & 2 \cdot 5\end{array}$ & $\begin{array}{l}1 \cdot 4 \\
2 \cdot 4\end{array}$ & $\begin{array}{ll}1 \cdot 4 & 1 \cdot 5 \\
2 \cdot 4 & 2 \cdot 5\end{array}$ \\
\hline $6 \mathrm{~S}_{1 \cdot 3}$ & $x$ & $x$ & $x$ & $x$ & $\begin{array}{l}1 \cdot 2 \\
2 \cdot 3\end{array}$ & $\begin{array}{ll}1 \cdot 2 & 1 \cdot 3 \\
2 \cdot 3 & 3 \cdot 3\end{array}$ & $\begin{array}{ll}1 \cdot 2 & 1 \cdot 4 \\
2 \cdot 3 & 3 \cdot 4\end{array}$ & $\begin{array}{ll}1 \cdot 2 & 1 \cdot 5 \\
2 \cdot 3 & 3.5\end{array}$ & $\begin{array}{l}1 \cdot 3 \\
3 \cdot 3\end{array}$ & $\begin{array}{ll}1 \cdot 3 & 1 \cdot 4 \\
3 \cdot 3 & 3 \cdot 4\end{array}$ & $\begin{array}{lll}1 \cdot 3 & 1 \cdot 5 \\
3.3 & 3.5\end{array}$ & $\begin{array}{l}1 \cdot 4 \\
3 \cdot 4\end{array}$ & $\begin{array}{ll}1.4 & 1.5 \\
3.4 & 3.5\end{array}$ \\
\hline c $S_{1.4}$ & $x$ & $x$ & $x$ & $x$ & $\begin{array}{l}1 \cdot 2 \\
2 \cdot 4\end{array}$ & $\begin{array}{ll}1 \cdot 2 & 1 \cdot 3 \\
2 \cdot 4 & 3 \cdot 4\end{array}$ & $\begin{array}{ll}1 \cdot 2 & 1 \cdot 4 \\
2 \cdot 4 & 4 \cdot 4\end{array}$ & $\begin{array}{ll}1 \cdot 2 & 1 \cdot 5 \\
2 \cdot 4 & 4 \cdot 5\end{array}$ & $\begin{array}{l}1 \cdot 3 \\
3 \cdot 4\end{array}$ & $\begin{array}{ll}1 \cdot 3 & 1 \cdot 4 \\
3 \cdot 4 & 4 \cdot 4\end{array}$ & $\begin{array}{ll}1 \cdot 3 & 1 \cdot 5 \\
3 \cdot 4 & 4 \cdot 5\end{array}$ & $\begin{array}{l}1 \cdot 4 \\
4 \cdot 4\end{array}$ & $\begin{array}{ll}1 \cdot 4 & 1 \cdot 5 \\
4 \cdot 4 & 4 \cdot 5\end{array}$ \\
\hline$d \mathrm{~S}_{1 \cdot 5}$ & $x$ & $x$ & $\times$ & $x$ & $\begin{array}{l}1 \cdot 2 \\
2 \cdot 5\end{array}$ & $\begin{array}{ll}1.2 & 1.3 \\
2.5 & 3.5\end{array}$ & $\begin{array}{ll}1.2 & 1.4 \\
2.5 & 4.5\end{array}$ & $\begin{array}{ll}1.2 & 1.5 \\
2.5 & 5.5\end{array}$ & $\begin{array}{l}1 \cdot 3 \\
3 \cdot 5\end{array}$ & $\begin{array}{ll}1.3 & 1.4 \\
3.5 & 4.5\end{array}$ & $\begin{array}{ll}1.3 & 1.5 \\
3.5 & 5.5\end{array}$ & $\begin{array}{l}1 \cdot 4 \\
4 \cdot 5\end{array}$ & $\begin{array}{ll}1.4 & 1.5 \\
4.5 & 5.5\end{array}$ \\
\hline$\left(e \mathrm{~S}_{2 \cdot 2}\right.$ & & & & & $x$ & $x$ & $x$ & $x$ & $2 \cdot 3$ & $2 \cdot 3 \quad 2 \cdot 4$ & $2 \cdot 3 \quad 2 \cdot 5$ & $2 \cdot 4$ & $2.4 \quad 2.5$ \\
\hline$f \mathrm{~S}_{2 \cdot 3}$ & & & & & $x$ & $x$ & $x$ & $x$ & $\begin{array}{l}2 \cdot 3 \\
3 \cdot 3\end{array}$ & $\begin{array}{ll}2 \cdot 3 & 2 \cdot 4 \\
3 \cdot 3 & 3 \cdot 4\end{array}$ & $\begin{array}{ll}2 \cdot 3 & 2 \cdot 5 \\
3 \cdot 3 & 3 \cdot 5\end{array}$ & $\begin{array}{l}2 \cdot 4 \\
3 \cdot 4\end{array}$ & $\begin{array}{ll}2.4 & 2.5 \\
3.4 & 3.5\end{array}$ \\
\hline$g \mathrm{~S}_{2 \cdot 4}$ & & & & & $x$ & $x$ & $x$ & $x$ & $\begin{array}{l}2 \cdot 3 \\
3 \cdot 4\end{array}$ & $\begin{array}{ll}2 \cdot 3 & 2 \cdot 4 \\
3 \cdot 4 & 4 \cdot 4\end{array}$ & $\begin{array}{ll}2 \cdot 3 & 2 \cdot 5 \\
3 \cdot 4 & 4 \cdot 5\end{array}$ & $\begin{array}{l}2 \cdot 4 \\
4 \cdot 4\end{array}$ & $\begin{array}{ll}2 \cdot 4 & 2 \cdot 5 \\
4.4 & 4.5\end{array}$ \\
\hline$h \mathrm{~S}_{2 \cdot B}$ & & & & & $x$ & $x$ & $x$ & $x$ & $\begin{array}{l}2 \cdot 3 \\
3 \cdot 5\end{array}$ & $\begin{array}{ll}2 \cdot 3 & 2 \cdot 4 \\
3 \cdot 5 & 4 \cdot 5\end{array}$ & $\begin{array}{ll}2 \cdot 3 & 2 \cdot 5 \\
3 \cdot 5 & 5 \cdot 5\end{array}$ & $\begin{array}{l}2 \cdot 4 \\
4 \cdot 5\end{array}$ & $\begin{array}{ll}2 \cdot 4 & 2 \cdot 5 \\
4 \cdot 5 & 5 \cdot 5\end{array}$ \\
\hline$k S_{3 \cdot 3}$ & & & & & & & & & $x$ & $x$ & $x$ & $3 \cdot 4$ & $3.4 \quad 3.5$ \\
\hline$m \mathrm{~S}_{3 \cdot 4}$ & & & & & & & & & $x$ & $x$ & $x$ & $\begin{array}{l}3 \cdot 4 \\
4 \cdot 4\end{array}$ & $\begin{array}{ll}3 \cdot 4 & 3 \cdot 5 \\
4 \cdot 4 & 4 \cdot 5\end{array}$ \\
\hline$n \mathrm{~S}_{3 \cdot 6}$ & & & & & & & & & $x$ & $x$ & $x$ & $\begin{array}{l}3.4 \\
4.5\end{array}$ & $\begin{array}{ll}3.4 & 3.5 \\
4.5 & 5.5\end{array}$ \\
\hline$\left\{p \mathrm{~S}_{1 \cdot a}\right.$ & & & & & & & & & & & & $x$ & $x$ \\
\hline$q q \mathrm{~S}_{\mathrm{a} \cdot \mathrm{s}}$ & & & & & & & & & & & & $x$ & $x$ \\
\hline
\end{tabular}

By substituting $\alpha$ for $\beta$ in (2) and (3) and solving for $a$ and $e$, we obtain

$$
a=(\mathrm{I}-\alpha)-\sqrt{\mathrm{I}-2 \alpha}
$$

and

$$
e x=2(I-\alpha)(I-\alpha)-2 \sqrt{(1-\alpha)(I-\alpha)(I-2 \alpha)}-\alpha^{2}
$$


Turning now to the relationships of $\mathrm{S}_{1.3}, \mathrm{~S}_{2.3}, \mathrm{~S}_{3.3}$ and $\mathrm{S}_{3}$ at equilibrium, we find, respectively, that

$$
\begin{gathered}
\alpha(\gamma+f+k)=2 b(\mathrm{I}-\alpha) \\
a(\gamma+f+k)+(\alpha+e)(\gamma+b+k)=2 f(\mathrm{I}-\alpha) \\
b(\gamma+f+k)+f(\gamma+k)=2 k(\mathrm{I}-\alpha) \\
(\gamma+f+k)(\alpha-a-b)+(\gamma+k)(\alpha-e-f)+2(\gamma+k)(\mathrm{I}-2 \alpha-\gamma) \\
+2(b+f)(\mathrm{I}-2 \alpha)+b(\alpha-e)=2 \gamma(\mathrm{I}-\alpha)
\end{gathered}
$$

Equation (10), with the aid of (2), (3), (7), (8) and (9), simplifies to

$$
(\gamma+k)(\mathrm{I}-\gamma)=(\gamma+k)(\mathrm{I}-\alpha)
$$

whence, since $\gamma+k \neq 0, \quad \gamma=\alpha$

The condition that the $S_{3}$ phenotype maintains constant proportion in the population is, therefore, that its proportion be the same as that of the $S_{1}$ phenotype.

By substituting $\alpha$ for $\gamma$ in (7), (8) and (9), we find that

$$
\begin{aligned}
2 \alpha b & =\sqrt{2 a}[(\mathrm{I}-\alpha) \sqrt{\mathrm{I}-2 \alpha}-\sqrt{(\mathrm{I}-\alpha)(\mathrm{I}-3 \alpha)}] \\
\alpha f & =(\alpha+a) b \\
2 \alpha k & =2(\mathrm{I}-\alpha)(\mathrm{I}-2 \alpha)-2 \sqrt{(\mathrm{I}-\alpha)(\mathrm{I}-2 \alpha)(\mathrm{I}-3 \alpha)}-2 \alpha^{2}
\end{aligned}
$$

If expressions for $\mathrm{S}_{1.4}, \mathrm{~S}_{2.4}, \mathrm{~S}_{3.4}, \mathrm{~S}_{4.4}$ and $\mathrm{S}_{4}$ proportions are now obtained, we find that their equilibrium conditions are defined by

$$
\begin{gathered}
\alpha(\delta+g+m+p)=2 c(\mathrm{I}-\alpha) \\
a(\delta+g+m+p)+(\alpha+e)(\delta+c+m+p)=2 g(\mathrm{I}-\alpha) \\
b(\delta+g+m+p)+f(\delta+c+m+p)+(\alpha+k)(\delta+c+g+p)=2 m(\mathrm{I}-\alpha) \\
c(\delta+g+m+p)+g(\delta+m+p)+m(\delta+p)=2 p(\mathrm{I}-\alpha) \\
(\delta+g+m+p)(\alpha-a-b-c)+(\delta+m+p)(\alpha-e-f-g)+(\delta+p)(\alpha-k-m) \\
+2(\delta+p)(\mathrm{I}-3 \alpha-\delta)+2(c+g+m)(\mathrm{I}-3 \alpha)+c(\alpha-e-f) \\
+(c+g)(\alpha-k)=2 \delta(\mathrm{I}-\alpha)
\end{gathered}
$$

Equation ( 18 ), by eliminating $a, b, c, e, f, g, k$ and $m$ with the aid of relationships already established, can be put into the form

$$
(\delta+p)(\mathrm{I}-\delta)=(\delta+p)(\mathrm{I}-\alpha)
$$

whence, since $\delta+p \neq 0, \quad \delta=x$

The $\mathrm{S}_{4}$ phenotype will maintain equilibrium, therefore, if it is present in the same proportion as the $S_{1}$ phenotype. 
By substituting $\alpha$ for $\delta$ in (I4), ( 15 ), (I6) and ( 17 ) we find

$$
\begin{aligned}
& 3 \alpha^{2} c=b \times[\sqrt{\mathrm{I}-2 \alpha}+\sqrt{(\mathrm{I}-\alpha)(\mathrm{I}-3 \alpha)}] \times \\
& {[\sqrt{(\mathrm{I}-\alpha)(\mathrm{I}-3 \alpha)}-\sqrt{\mathrm{I}-4 \alpha}] } \\
& \alpha g=(\alpha+a) c \\
& a(2-3 \alpha) m=c \times[(\alpha-a)-\sqrt{2 a(\mathrm{I}-\alpha)(\mathrm{I}-3 \alpha)}] \\
& 3 \alpha p=2(\mathrm{I}-\alpha)(\mathrm{I}-3 \alpha)-2 \sqrt{(\mathrm{I}-\alpha)(\mathrm{I}-3 \alpha)(\mathrm{I}-4 \alpha)}-3 \alpha^{2}
\end{aligned}
$$

The process of finding $r$ equations relating to the stability of proportions of $\mathrm{S}_{1, r}, \mathrm{~S}_{2, r}, \mathrm{~S}_{3, r} \ldots \mathrm{S}_{r . r}$ and using these, and earlier established relationships, to resolve the equation for $\mathrm{S}_{r}$ can be continued indefinitely, but the process becomes more and more tedious. The analysis has so far established that at equilibrium $\alpha=\beta=\gamma=\delta$, and there is no reason to suppose that this simple relationship between the proportions of the first four phenotypes will be different for others. The equation which states the condition that the $r$ th phenotype maintains a constant proportion, $\rho$, in the population appears always to take the form (a formal proof of this has not been found possible)

$$
(\rho+x)(\mathrm{I}-\rho)=(\rho+x)(\mathrm{I}-\alpha)
$$

where $x$ is the proportion of $\mathrm{S}_{r, r}$ in the population. This expression immediately gives

$$
p=\alpha
$$

If, then, $\alpha=\beta=\gamma=\delta \ldots=\rho=\ldots$, we have from (I)

$$
\alpha=n \alpha^{2}, \text { or } \alpha=\mathrm{I} / n
$$

By substituting $\mathrm{I} / n$ for $\alpha$ in (6), (13) and (22) we find that the proportions $\left(p_{2.2}, p_{3.3}, p_{4.4}\right)$ of the first three homozygotes at equilibrium are

$$
\begin{aligned}
n p_{2.2} & =2(n-\mathrm{I})(n-\mathrm{I})-2 \sqrt{n(n-\mathrm{I})(n-\mathrm{I})(n-2)}-\mathrm{I} \\
2 n p_{3.3} & =2(n-\mathrm{I})(n-2)-2 \sqrt{n(n-\mathrm{I})(n-2)(n-3)}-2 \\
3 n p_{4.4} & =2(n-\mathrm{I})(n-3)-2 \sqrt{n(n-\mathrm{I})(n-3)(n-4)}-3
\end{aligned}
$$

These expressions clearly follow a set pattern. In general $(r-\mathrm{I}) n p_{r . r}=2(n-\mathrm{I})(n-r+\mathrm{I})-2 \sqrt{n(n-\mathrm{I})(n-r+\mathrm{I})(n-r)}-(r-\mathrm{I})$

Turning to the expressions for the proportions of $\mathrm{S}_{1.2}, \mathrm{~S}_{1.3}$ and $\mathrm{S}_{1.4}$ at equilibrium, we have, from (5), (II) and (19) respectively

$$
\begin{aligned}
p_{1.2} & =[(n-\mathrm{I})-\sqrt{n(n-2)}] / n \\
2 p_{1.3} & =p_{1.2} \times[\sqrt{n(n-\mathrm{I})}+\sqrt{(n-\mathrm{I})(n-2)}][\sqrt{(\overline{(n-\mathrm{I})(n-2)}-\sqrt{n(n-3)}}] \\
3 p_{1.4} & =p_{1.3} \times[\sqrt{n(n-2)}+\sqrt{(n-\mathrm{I})(n-3)}][\sqrt{(\overline{(n-\mathrm{I})(n-3)}-\sqrt{n(n-4)}}]
\end{aligned}
$$


These formulæ, again, follow a set pattern; in general

$$
\begin{aligned}
& (r-\mathrm{I}) p_{1 . r}=p_{1 . r-1} \\
& \quad \times[\sqrt{n(n-r+2)}+\sqrt{(n-\mathrm{I})(n-r+\mathrm{I})}][\sqrt{(n-\mathrm{I})(n-r+\mathrm{I})}-\sqrt{n(n-r)}]
\end{aligned}
$$

Equations (12) and (20) suggest that the proportion of $S_{2 . r}$ is obtainable from that of $S_{1 . r}$ by multiplying by the factor $(\alpha+a) / \alpha$, which, in terms of $n$, is $n-\sqrt{n(n-2)}$ :

$$
\begin{aligned}
& p_{2.3}=p_{1.3} \times[n-\sqrt{n(n-2)}] \\
& p_{2.4}=p_{1.4} \times[n-\sqrt{n(n-2)}]
\end{aligned}
$$

In the same way, $S_{3 . r}$ genotype proportions are derived from $S_{1 . r}$ proportions by multiplying by another factor, which is (from (2I))

$$
[n+\sqrt{n(n-2)}][\sqrt{n(n-2)}-\sqrt{(n-1)(n-3)}] /(2 n-3)
$$

The mode of formation of multipliers for converting $\mathrm{S}_{1, p}$ proportions to $S_{r, p}$ proportions has not been ascertained for writing down by inspection. Their computation, however, is not difficult. It can be shown that the factor for converting $p_{1}$, to $p_{r}$, takes the form

$$
\left(\mathrm{I}-n p_{r . r}\right) /\left(\mathrm{I}-n p_{1.2}-n p_{1.3}-\ldots-n p_{1 . r}\right)
$$

all the terms of which are already known. Having calculated the values of $p_{1.2}, p_{1.3}, p_{1.4} . . p_{1 . r} . . p_{1 . n}$, they are converted into $p_{2.3}, p_{2.4} .$. $p_{2, r} \ldots p_{2, n}$, then into $p_{3.4} \ldots p_{3, r} \ldots p_{3 . n}$, and so on, by a relatively simple process.

The formulæ given in (23), (24), (25) and (26) have been used to compute the equilibrium proportions of all $\frac{1}{2}(n-I)(n+2)$ genotypes in populations containing three, four and five $\mathrm{S}$ alleles in serial dominance.

For three alleles:

$$
\begin{aligned}
& \text { (24) } p_{1.2}=(2-\sqrt{ } 3 \times \mathrm{I}) / 3=(2-\sqrt{ } 3) / 3 \\
& \text { per cent. per cent. } \\
& \text { (25) } 2 p_{1.3}=(2-\sqrt{ } 3) / 3 \times(\sqrt{ } 6+\sqrt{ } 2)(\sqrt{ } 2-0) \\
& p_{1.3}=(\sqrt{ } 3-1) / 3 \\
& =8 \cdot 93 \\
& =24 \cdot 4 \mathrm{I} \\
& 33 \cdot 34 \\
& \text { (23) } 3 p_{2.2}=2 \times 2 \times 2-2 \sqrt{3 \times 2 \times 2 \times 1}-I \\
& p_{2.2}=(7-4 \sqrt{ } 3) / 3=2 \cdot 39 \\
& \text { (26) } \quad p_{2.3}=(\sqrt{ } 3-1) / 3 \times(1-7+4 \sqrt{ } 3) /(1-2+\sqrt{ } 3) \\
& =(4 \sqrt{ } 3-6) / 3 \\
& =30 \cdot 94 \\
& p_{3.3}=\mathrm{I} / 3 \\
& \mathrm{~S}_{2}=22 \cdot 32 \text { per cent. } \\
& \mathrm{S}_{3}=6 \mathrm{I} \cdot \mathrm{OI} \text { per cent. }
\end{aligned}
$$


The calculated values are the same as those given by Bateman (1952) for Scheme J with three alleles.

For four alleles in serial dominance $\left(S_{1}>S_{2}>S_{3}>S_{4}\right)$, the genotype proportions and allele frequencies at equilibrium are:

$$
\begin{aligned}
& p_{1.2}=(3-2 \sqrt{ } 2) / 4 \\
& p_{1.3}=(\sqrt{ } 2-\mathrm{I})(3-\sqrt{ } 6) / 4 \\
& p_{1.4}=(\sqrt{ } 2-\mathrm{I})(\sqrt{ } 6-\mathrm{I}) / 4 \\
& p_{2.2}=(\mathrm{I} 7-\mathrm{I} 2 \sqrt{ } 2) / 4 \\
& p_{2.3}=(3 \sqrt{ } 2-4)(3-\sqrt{ } 6) / 2 \\
& p_{2.4}=(3 \sqrt{ } 2-4)(\sqrt{ } 6-\mathrm{I}) / 2 \\
& \text { per cent. per cent. } \\
& =4.29 \\
& =5 \cdot 70 \\
& =\mathrm{I} 5 . \mathrm{OI} \\
& p_{3.3}=(5-2 \sqrt{ } 6) / 4 \\
& p_{3.4}=(4-\sqrt{ } 6)(\sqrt{ } 6-1) / 10 \\
& =2 \cdot 53 \\
& =22 \cdot 47 \\
& =0.74 \\
& =6.67 \\
& =\mathrm{I} 7.59 \\
& 25 \cdot 00 \\
& 25 \cdot 00 \\
& p_{4.4}=\mathrm{I} / 4 \\
& \begin{array}{l}
S_{1}=12.50 \text { per cent. } \\
S_{2}=15.01 \text { per cent. } \\
S_{3}=19.96 \text { per cent. } \\
S_{4}=52.53 \text { per cent. }
\end{array} \\
& 25 \cdot 00 \\
& =25 \cdot 00
\end{aligned}
$$

With five alleles in serial dominance, the proportions of the I4 genotypes and the frequencies of the alleles at equilibrium are:

$$
\begin{array}{ll}
p_{1.2}=\left(4-\sqrt{ }{ }_{5}\right) / 5 & =2 \cdot 54 \\
p_{1.3}=(\sqrt{ } 5-\sqrt{ } 3)(2 \sqrt{ } 3-\sqrt{ } 10) / 5 & =3.04 \\
p_{1.4}=(\sqrt{ } 5-\sqrt{ } 3)(\sqrt{ } 10-\sqrt{ } 3)(4-\sqrt{ } 10) / 15 & =4.03 \\
p_{1.5}=(\sqrt{ } 5-\sqrt{ } 3)(\sqrt{ } 10-\sqrt{ } 3)(\sqrt{ } 10-1) / 15 & =10.39
\end{array}
$$

per cent. per cent.

$$
\begin{aligned}
& p_{2.2}=(3 \mathrm{I}-8 \sqrt{ } \mathrm{I} 5) / 5 \\
& =0 \cdot 32 \\
& p_{2.3}=(5-\sqrt{ } \text { I } 5)(\sqrt{ } 5-\sqrt{ } 3)(2 \sqrt{ } 3-\sqrt{ } \text { I0 }) / 5=3.43 \\
& p_{2.4}=\left(5-\sqrt{ }{ }_{1}\right)(\sqrt{ } 5-\sqrt{ } 3)(\sqrt{ } 10-\sqrt{ } 3)(4-\sqrt{ } 10) / 15
\end{aligned}
$$

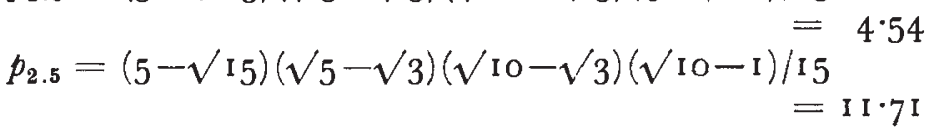

$$
\begin{array}{ll}
p_{3.3}=(\mathrm{I} 1-2 \sqrt{ } 30) / 5 & =0.9 \mathrm{I} \\
p_{3.4}=2(\sqrt{ } 30-5)(4-\sqrt{ } \mathrm{I} 0) / \mathrm{I} 5 & =5.33 \\
p_{3.5}=2(\sqrt{ } 30-5)(\sqrt{ } \mathrm{I} 0-\mathrm{I}) / \mathrm{I} 5 & =\mathrm{I} 3.76
\end{array}
$$




$$
\begin{aligned}
& p_{4.4}=(13-4 \sqrt{ } \text { I0 }) / 15 \\
& p_{4.5}=2(5-\sqrt{ } \text { I0 })(\sqrt{ } 10-1) / 45
\end{aligned}
$$

per cent. per cent.

$=2 \cdot 34$

$=17 \cdot 66$

$20 \cdot 00$

$$
\begin{aligned}
& p_{5.5}=1 / 5 \quad \\
& \mathrm{~S}_{1}=10.00 \text { per cent. } \\
& \mathrm{S}_{2}=11.43 \text { per cent. } \\
& \mathrm{S}_{3}=13.69 \text { per cent. } \\
& \mathrm{S}_{4}=18.12 \text { per cent. } \\
& \mathrm{S}_{5}=46.76 \text { per cent. }
\end{aligned}
$$

$=20 \cdot 00$

An examination of the proportions reveals that the bottom-recessive homozygote is the most abundant element in the population when equilibrium has been attained; as, indeed, it must be, since this genotype alone represents one of the equally proportioned phenotypes. The bottom-recessive allele has the highest frequency in the population, and the equilibrium proportions of the other alleles are related to their position in the scale of dominance. Recessivity, in SI populations of this kind, always enjoys selective advantage.

The minimum number of alleles for operation of the system is three. It is clear that a population which contained equal proportions of, say, $\mathrm{S}_{2.3}$ and $\mathrm{S}_{3.3}$ genotypes would be in equilibrium; but in order that $S_{3.3}$ homozygotes should ever appear the intervention of an allele dominant to $\mathrm{S}_{2}$ and $\mathrm{S}_{3}$ would first be necessary-unless, of course, the incompatibility mechanism occasionally broke down to allow the selfing of $S_{2.3}$ to give $S_{3.3}$ segregants.

The simplicity manifest in systems in which the alleles show serial dominance is lost when alleles of individual action also occur, for each phenotype no longer represents I $/ n$th part of the whole when the population is in equilibrium. Alleles individual in action, it seems, are equally frequent in the population; this fact helps but little in computing genotype frequencies, merely reducing the number of simultaneous equations for solution. Two analyses have been made of the effect of having a pair of alleles of individual action in a 3 -allele system. More complex cases have proved to be insoluble.

Where $S_{1}=S_{2}>S_{3}$, four genotypes only are present in the population, $S_{2.2}$, like $S_{1.1}$, being absent. The proportions of these four genotypes and allele frequencies at equilibrium are:

$$
\begin{array}{lll}
\mathrm{S}_{1.2} & 5 \cdot 76 \text { per cent. } & \mathrm{S}_{1} 16 \cdot 32 \text { per cent. } \\
\mathrm{S}_{1.3} & 26 \cdot 87 \text { per cent. } & \mathrm{S}_{2} 16.32 \text { per cent. } \\
\mathrm{S}_{2.3} & 26 \cdot 87 \text { per cent. } & \mathrm{S}_{3} 67 \cdot 36 \text { per cent. } \\
\mathrm{S}_{3.3} & 40 \cdot 50 \text { per cent. } &
\end{array}
$$

The proportions here are not simple irrational quantities. They are derived from the solution of a bi-quadratic equation which has one zero, one real and two imaginary roots. 
In a population where $S_{1}>S_{2}=S_{3}$, the genotype proportions and allele frequencies at equilibrium are:

$$
\begin{array}{ll}
\mathrm{S}_{1.2}=(6-\sqrt{ } 6) / 15=23 \cdot 67 \text { per cent. } & \\
\mathrm{S}_{1.3}=(6-\sqrt{ } 6) / \mathrm{I} 5=23 \cdot 67 \text { per cent. } & \mathrm{S}_{1} 23 \cdot 67 \text { per cent. } \\
\mathrm{S}_{2.2}=(6-\sqrt{ } 6) / 30=1 \mathrm{I} \cdot 84 \text { per cent. } & \mathrm{S}_{2} 38 \cdot 16 \text { per cent. } \\
\mathrm{S}_{2.3}=(\sqrt{ } 6-\mathrm{I}) / 5=28 \cdot 99 \text { per cent. } & \mathrm{S}_{3} 38 \cdot 16 \text { per cent. } \\
\mathrm{S}_{3.3}=(6-\sqrt{ } 6) / 30=\mathrm{I} \cdot 84 \text { per cent. } &
\end{array}
$$

\section{POPULATIONS CONTAINING SC AND SI COMPONENTS}

The mutation of an active $\mathrm{S}$ allele into an inactive amorph would always be conserved in a cacao population, provided that the flower in which it arose was compatibly cross-pollinated or was used as pollen parent in a compatible cross. Amongst the progeny of such a cross would appear one SI genotype heterozygous for the mutant allele. Half of the progeny of this heterozygote with any compatible genotype would be heterozygous for the amorph; and, provided the compatible genotype was not homozygous for an $\mathrm{S}$ allele, these would fall into two cross-compatible groups. Once a successful sib-pollination was made homozygous $\mathrm{S}_{f . f}$ genotypes would emerge. A similar argument applies to the case where mutation of either of the "wild type" A and B loci to an inactive mutant took place. Such SC trees, homozygous for an inactive mutant, will be reciprocally cross-compatible with any other element of the population.

Analysis has been confined to a consideration of cases where the $\mathrm{S}_{f}$ amorph penetrates into populations originally comprising only $\mathrm{SI}$ types in equilibrium. The deductions made from the analysis are, however, applicable to the case where self-compatibility results from homozygosity at the mutated A or B locus, the mutant being inactive.

Taking the simplest possible case for analysis-the penetration of the $\mathrm{S}_{f}$ allele into a population originally containing, at equilibrium, equal proportions of $S_{1.2}$ and $S_{2.2}$ trees--there will be five genotypes, $\mathrm{S}_{1.2}, \mathrm{~S}_{1 . f}, \mathrm{~S}_{2.2}, \mathrm{~S}_{2 . f}$ and $\mathrm{S}_{f . f}$, present in the population. If the frequencies of these, at any instant of time, are respectively denoted by $v, w, x$, $y$ and $z$, it can be shown that the equations relating to equilibrium in the population are simultaneously satisfied by two, and only two solutions; the sum of $v$ and $w$ must be either zero or one-half. When $v+w$ is zero, $z$ is unity, so that the population consists entirely of $\mathrm{S}_{f . f}$ trees. When $v+w=\frac{1}{2}, v=x=\frac{1}{2}$ and the population contains only the SI $\mathrm{S}_{1,2}$ and $\mathrm{S}_{2,2}$ genotypes in equal proportion, the state, in fact, of the population before the presence of the $\mathrm{S}_{f}$ allele was established. We are left, then, with the conclusion that the population will maintain equilibrium only if the $\mathrm{S}_{f, f}$ tree is wholly absent, or if it is the sole genotype.

Analyses of genotype proportions, carried out for several successive mating cycles, clearly show that once the $\mathrm{S}_{f}$ allele is present in the population it is not eliminated; the condition where $v+w=\frac{1}{2}$ is 
not recovered. Instead, the genotype proportions change with each successive generation until the $\mathrm{S}_{f, f}$ genotype is the only one in the population.

Of the five genotypes present in the population during its conversion from SI to wholly $S C$ status, the $S_{2.2}$ genotype experiences the greatest initial change in frequency, dropping away very rapidly from its original 50 per cent. incidence and then, with lessening rapidity, eventually disappearing altogether. The $S_{1.2}$ genotype suffers a similar fate but with less rapid attenuation than in the case of $\mathrm{S}_{2.2}$. The $\mathrm{S}_{1, f}$ and $\mathrm{S}_{2 . f}$ frequencies both build up to maxima and then drop towards zero; at all times the $\mathrm{S}_{2 . f}$ frequency is greater than that of $\mathrm{S}_{1 . f}$. Whilst these changes are taking place, the $\mathrm{S}_{f . f}$ genotype makes accelerating progress towards becoming the sole genotype in the population. Fig. I shows these trends graphically.

Full analyses have not been made for populations containing more than two active $S$ alleles (as well as $S_{f}$ ) but it appears that trends similar to those mentioned above are inevitable. SC and SI cacao trees cannot coexist in equilibrium in an isolated population. The SG type ultimately displaces the SI genotypes. The element most rapidly eliminated is the homozygote of the bottom-recessive active $\mathrm{S}$ allele. The genotype which becomes the predominant SI element, for some time sharing the scene with the SC genotype, is that which carries, with $\mathrm{S}_{f}$, this same bottom-recessive allele. Active $\mathrm{S}$ alleles are reduced in frequency according to their dominance, the top-dominant being the most quickly attenuated by the penetration of $\mathrm{S}_{f}$, followed by the others in order. The rapidity with which these changes are brought about is influenced by the ratio of the average amount of self-setting to the average amount of cross-setting on the SC trees. Voelcker (1937) showed that the SC tree in Trinidad can often set as many fruits from self-pollination as from cross-pollination. The progeny arising from selfings will all be $\mathrm{SC}$; progeny from crossings will be SI and SC. The proportion of SC trees in any generation, therefore, will be determined by the intensity of self-setting on the SC trees of earlier generations. Cope (1939) showed that SC trees, in a population which contained SI and SC individuals in approximately equal proportion, produced an average of 66 per cent. more fruit than the SI tree; such heavier cropping will tend to give the SC tree still greater breeding advantage over the SI tree.

\section{DISCUSSION}

The centre of origin of Theobroma cacao has been placed by Cheesman (1944) on the eastern equatorial slopes of the Andes. The relatively small amounts of material collected in and near this region have so far proved to be uniformly SI. Further removed from the hypothetical centre of origin SC types are encountered-in the Colombian valleys of the Cauca and Magdalena rivers, in Central America, in the lower Amazon valley, in Venezuela and in Trinidad. The vast 
population of cacao trees in West Africa, which provides the bulk of the world's cacao, is uniformly SC and is reputed to have stemmed from an originally small amount of material collected near the mouth of the Amazon. How close to the centre of origin SC trees are to be found, or whether they are actually present in the area, is not known.

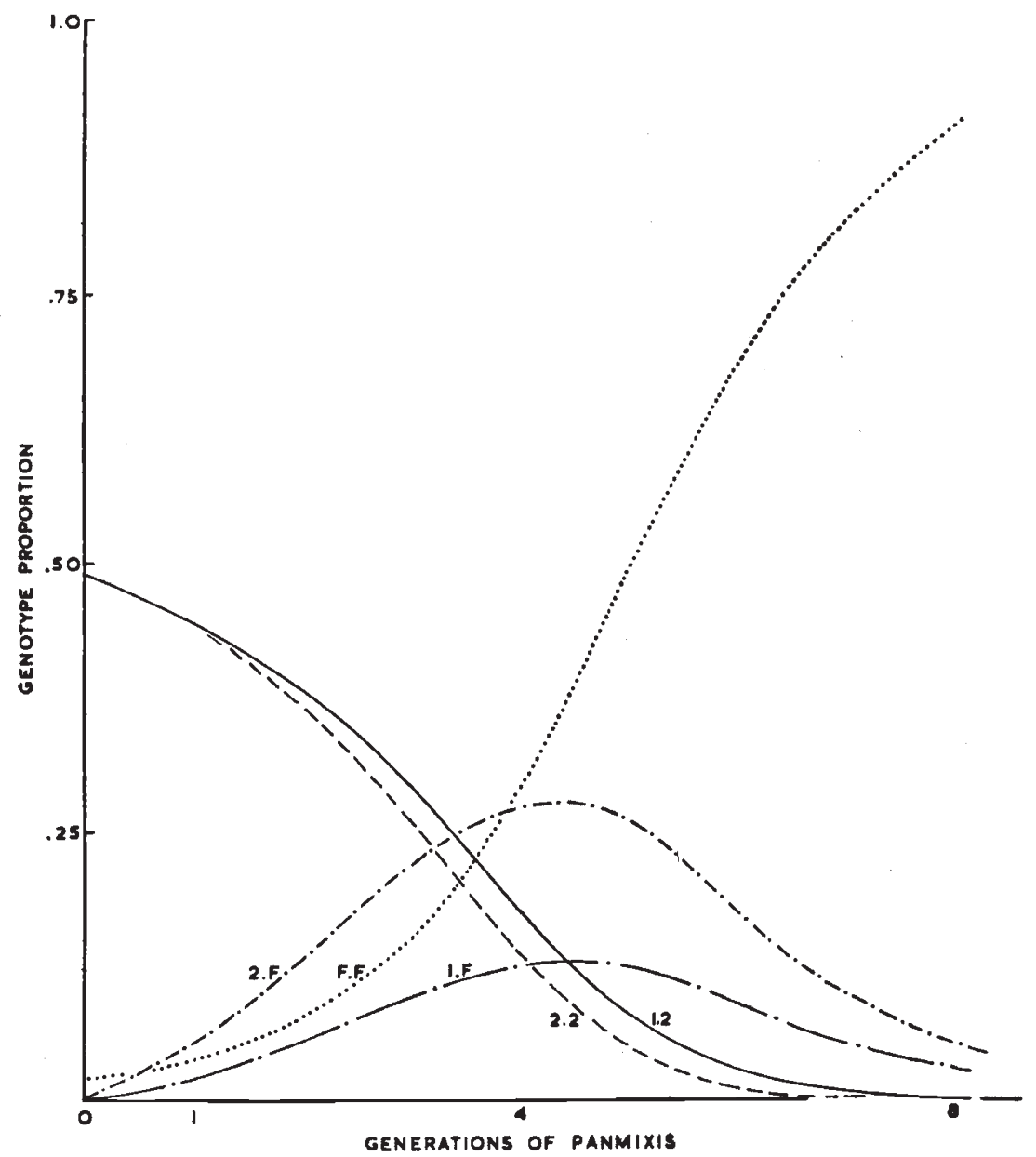

Fig. 1.-Proportions of $S_{1 \cdot 2}, S_{1 \cdot f}, S_{2 \cdot 2}, S_{2 \cdot f}$ and $S_{1 \cdot f}$ genotypes in relation to number of generations of panmixis, starting with arbitrarily chosen proportions of 0.49 for $S_{1 \cdot 2}$, 0.49 for $\mathrm{S}_{2 \cdot 2}$ and 0.02 for $\mathrm{S}_{f . p}$. The assumption is made that equal numbers of selfed and crossed progenies are borne on the $S_{f, g}$ types.

The emergence of fully SC types in a species which was otherwise SI might assist in achieving a wide-spread distribution of the species. Many factors-life cycle, geography, population density, seed dispersal and physical size of the individuals, to mention a few-would, of course, be involved in determining how far self-compatibility was " useful " to the species. The persistence of the SI condition in cacao would make it necessary for groups of trees, showing cross-compatibility, 
to be established simultaneously at increasing distances from the centre of origin if the species was to continue to spread. Isolated SI trees on the fringes of the distribution would not fruit and so could not contribute to further spread; but SC trees, in similar circumstances, would always fruit and assist in the diffusion of the species. If selfcompatibility made its appearance at some point in the outward spread of $T$. cacao from its centre of origin, then any further extension of the species in space might be realized more rapidly by the SC tree than by the SI. Such little knowledge as we possess of the distribution of SC and SI cacao types might seem, at first sight, to support this view. But the question arises-why have the SC types not taken over all cacao populations in South and Central America? Outbreeding, associated with the SI condition, is usually assumed to be advantageous to a species; but the analyses presented in this paper show unmistakably that self-compatibility carries very marked breeding advantage. The mutation of active $\mathrm{S}$ alleles to the inactive amorph, and of the $A$ and $B$ loci to inactive mutants must have occurred regularly in the evolutionary history of cacao, even at and near the centre of origin, so that the apparent absence of SC types in this area and the continuing presence of SI types in remoter areas suggest the operation of some strong selective discrimination against SC types.

\section{SUMMARY}

1. The phenotypes present in a population of SI cacao trees, containing any number of $S$ alleles in serial dominance, are equally proportioned when the population is in equilibrium.

2. Formulæ are presented for the calculation of the equilibrium frequencies of all $\frac{1}{2}(n-1)(n+2)$ genotypes in a population with $n$ $\mathrm{S}$ alleles in serial dominance. Recessivity shows selective advantage.

3. When alleles of individual action occur with those showing dominance relationships, the phenotype proportions are no longer equal at equilibrium and the computation of genotype frequencies becomes more difficult.

4. Where SC and SI genotypes are present together in an isolated population, equilibrium between then is impossible. The selective advantage of recessivity is so overwhelming in the case of the compatibility factor that the population comes eventually to contain only SC components, the SI genotypes having been eliminated.

\section{REFERENCES}

Bateman, A. J. 1952. Self-incompatibility in angiosperms. I-Theory. Heredity, $6,285-310$.

CHeEsman, E. E. 1944. Notes on the nomenclature, classification and possible relationships of cacao populations. Trop. Agriculture, Trin., 2I, I44-I 59.

COpE, F. W. 1939. Some factors controlling the yield of young cacao II. 8th Ann. Rep. on Cacao Res. (1938), Trinidad, 4-15. 
COPE, F. W. 1962. The mechanism of pollen incompatibility in Theobroma cacao L. Heredity, 17 , 157-182.

hNight, R., AND ROGERS, H. H. 1953. Sterility in Theobroma cacao L. Nature, London, 172,164 .

KNIGHT, R., AND Rogers, H. H. 1955. Incompatibility in Theobrona cacao. Heredity, $9,69-77$.

voelcker, o. J. 1937. Self-incompatibility in cacao, I. Gth Ann. Rep. on Cacao Res. (1936), Trinidad, $2-5$. 